\title{
El discurso patriarcal en los textos de los evangelios: un abordaje desde la teología feminista
}

\section{Ana Ruth Chinchilla Castillo}

Licenciada en Docencia de la UNED. Máster en Teología Católica de la UNED. Investigadora-Extensionista en la Vicerrectoría de Investigación de la UNED, en donde labora desde 1989. Correo electrónico: anaruthch@gmail.com

Recibido: 30 de marzo 2012 - Aceptado: 27 de junio 2013

\section{RESUMEN}

Se presenta una propuesta de lectura de los cuatro evangelios, desde una perspectiva conciliadora de la teología feminista. Se sabe que el texto bíblico contiene lenguaje excluyente y patriarcal; sin embargo, la postura que propongo pretende más bien la reconstrucción de la idea de la mujer y de su rol a partir de tal discurso y brindar un enfoque de la lectura bíblica pertinente y vigente, que se alimente con los aportes de nuevas relaciones y nuevos contextos vividos por las mujeres.

Palabras clave: Teología feminista, evangelios, nuevo testamento, patriarcado.

\section{ABSTRACT}

There is a proposal of reading the four Gospels in the Bible from a conciliatory perspective of feminist theology. It is known that discourse in the Bible contains exclusionary and patriarchal language, but my position rather intends to suggest the reconstruction -from that discourse- of the idea of a woman and her role, and provide a relevant approach to read the Bible fed by contributions given by new relationships and new contexts as women live them.

Key words: Feminist theology, New Testament, patriarchy, the Gospels.

"En efecto, quien comete una injusticia, es más infeliz que quien la sufre; después de todo, el injusto no destruye al otro, sino a sí mismo, pues deforma, cada vez más, la imagen de Dios". Jutta Burggraf

\section{Introducción}

En los textos de la Biblia, Dios se manifiesta para hacernos partícipes, como humanidad, de su plan salvífico. Como obra textual, la Biblia es un documento que se escribió hace miles de años, en un contexto social, cultural y geográfico muy diferente al que compartimos hoy, y, que por la naturaleza histórica del texto bíblico, es necesario que su mensaje sea releído y reinterpretado para 
hasta la venida del Espíritu Santo, y en las cartas posteriores escritas por los Apóstoles, en el Nuevo Testamento. En el Antiguo Testamento, por ejemplo, esta figura de la mujer aparece con diversos roles: como pecadora, como heroína, como esposa, como amante. Ya en el Nuevo Testamento, con la aparición de Jesús, que viene a cumplir el plan salvífico divino, se evidencia que el rol de la mujer puede ser diferente a partir de su relación con el Mesías.

Es entonces a partir de esta coyuntura histórica de relación desde la cual propongo mi análisis: ¿Cómo abordar el fenómeno mujer en el Nuevo Testamento? Para tal fin sugiero dos plataformas: el método histórico y la teología feminista. El Método Histórico, aunque pertinente, no resulta suficiente para entender el fenómeno, por lo que el echar mano de algunos postulados de la teología crítica feminista, como marco referencial para mi relectura, me brinda aportes pertinentes.

Al hablar de teología crítica feminista menciono algunas tesituras relevantes que me sirven de soporte para esta relectura, y que me permiten localizar en el Nuevo Testamento aquellos elementos discursivos que desde una perspectiva de género y a la luz de la fe, se pueden redimensionar con el fin de evidenciar un rol protagónico de la mujer en los textos bíblicos. Mi aproximación no es, entonces, un discurso feminista más.

Tampoco es este un documento que pretenda tomar una posición extrema o que fomente polarizar la discusión en torno al rol de la mujer en la Biblia y que lleve a sus extremos una diferencia, ya de por sí dada sexualmente en términos biológicos. Todo lo contrario; pretendo rescatar, a la luz de la fe, una posición analítica integrado$\mathrm{ra}$, que evidencie, resalte y revalore el papel de la mujer como elemento esencial en el plan de salvación de Dios; sugiero una interpretación alternativa a partir de una perspectiva de género que permita una visión integradora del hombre y de la mujer en la historia salvífica divina. Particularmente, pretendo con ello evidenciar y resaltar el rol protagónico de la mujer en los textos bíblicos del Nuevo Testamento.
Menciono en el análisis, además, algunos elementos enmarcados en el enfoque analítico histórico; no obstante, este no es tampoco un documento que pretenda ahondar en forma exhaustiva en una exploración histórico-literaria del mensaje de Dios; pero estos elementos serán útiles para que se tenga una visión general del contexto histórico y cultural en el cual se desenvolvía la mujer en los tiempos antiguos.

\section{Plataforma de abordaje}

\section{El método histórico}

Como señalé anteriormente, el método histórico representa una plataforma de abordaje importante en el análisis, pero no exclusiva. Esta herramienta permitirá comprender en un primer vistazo las razones por las cuales los protagonistas históricos de aquel momento se comportaban de cierta manera.

Aunque los evangelios no son informes históricos ni crónicas del pasado, es claro que están basados en datos y hechos reales (Sistema de Estudios de Posgrado UNED, 2007). Sin embargo, conceptos como fe y género quedan excluidos de estas consideraciones históricas. Como señala José María Casciano:

El método histórico es útil y en ciertos límites adecuado para investigar digamos el cañamazo, el tejido histórico, literario y cultural que soporta la Revelación; pero no es adecuado para penetrar en el sentido de esta y en la naturaleza de las realidades sobrenaturales. (Casciano, 1983: p. 47).

Casciano advierte - de manera acertada- sobre el cuidado que se debe tener al aplicar el método histórico en la exégesis bíblica, pues a pesar de ser "amplísimo, legítimo y útil", no debe "salirse de su objetivo formal e invadir el terreno de la fe y de la Teología" (1983: p. 49). Continúa, más adelante, diciendo que "desgajados de la fe católica (...) se ha empleado el método histórico no solo como juez de la Teología y de la fe, sino como instrumento para combatirlas. Esas circunstancias 
- esos abusos- no invalidan el método como tal, pero obligan a usarlo con cautela..." (idem: p. 50).

Indica Grelot, citado por Casciano (1983: p. 44), los dos criterios fundamentales que sigue este método, a saber:

- Interno: lengua, estilo literario, vocabulario, concordancia histórica entre sí de los datos del escrito.

- Externo: testimonio que otros documentos históricos aportan sobre el documento en cuestión.

Estos dos criterios confluyen en la investigación de la autenticidad del escrito en cuestión, la valoración de su veracidad y sinceridad en el tiempo, la riqueza y seguridad de la información y su fecha de composición.

Igual reserva expresa Etienne Charpentier (2001: p. 17) al mencionar que "los textos se refieren muchas veces a una historia concreta". Agrega que esos textos "forman parte de un contexto, de un conjunto" (p.18), alrededor del cual se plantean interrogantes como la época en la que se escribió el texto, el ambiente económico y la situación etnográfica, por mencionar algunas; también la situación del pueblo en ese momento en particular y el género del texto, así como el significado o sentido particular que tenían ciertas palabras o expresiones en ese contexto. Todo este bagaje hace que los aportes del método histórico sean innegables en aspectos de exégesis bíblica, tales como los géneros literarios, la índole literaria de los libros sagrados, los autores y el fondo histórico ambiental en que tales libros tuvieron su devenir.

El método histórico, no obstante, no puede por sí mismo, ni por los medios internos y externos, determinar si un escrito fue o no inspiración de Dios (recordemos que una de las principales limitaciones de este método es precisamente el peligro de reñir con la fe y la teología). Es de suma relevancia destacar que la Biblia presenta una memoria histórica de un pueblo que constantemente luchaba por mantener viva su fe en Dios, entre eventos históricos de opresión y de liberación. "El texto se va cargando de sentido en la historia posterior a su escrituración", dice $\mathrm{Pa}$ blo Richard (2002: p.10), y señala más adelante la importancia de conocer "el contexto económico, político, social, cultural y religioso" en el cual ese texto nació para reconocer en esa historia narrada la propia: una historia de liberación, de amor y de perdón, en la que se sufre persecuciones y en la que se atraviesa una constante lucha ante distintas adversidades. Hay que recordar que el linaje de David sufrió una gran ruptura: en el 722 a.C, los asirios terminaron con el reinado en Israel, y en el 587 a.C., los judíos fueron deportados a Babilonia. Se mantuvo una historia de conquistas, de deportaciones, de guerras y de subordinación, hasta que se cumplieron las profecías (Charpentier, 2001).

Con esta visión de mundo, aquellas sociedades basaban su economía y su visión en patrones definitiva y absolutamente patriarcales. Es comprensible-aunque no por tanto aceptable- el rol de subordinación que ocupaban las mujeres en ese entonces, pues fueron elementos que dentro de una lógica daban sostenimiento a una sociedad.

Por tanto, en los tiempos de Jesús, las lapidaciones no representaban un escándalo o un ultraje a los derechos humanos, como sí lo son en la actualidad. Tampoco se veía con malos ojos que las mujeres fueran mercadeadas o que fueran objetos propiedad de sus esposos. Por el contrario, este sistema representaba la sostenibilidad económica, moral y familiar de aquellas organizaciones.

El contexto social y cultural que ofrece este vistazo histórico de los textos bíblicos, evidencia una invisibilización de la mujer en otros ámbitos, la educación, por ejemplo, ya que solo los varones tenían acceso al estudio bíblico y a la reflexión. Los textos bíblicos, por su parte, son elementos que apoyaron este discurso androcéntrico. Es evidente que, al ser la Biblia escrita por varones, dentro de una cultura patriarcal, el discurso refleja una visión y una experiencia androcéntricas, no solo en su orientación hacia la posición que debía tener la mujer, sino también hacia todo un comportamiento que se puede llamar "varonil". 
La carga semántica conferida a la mujer ha sido un tipo de maldición que ella ha arrastrado por siglos. Textos como el Génesis - "el varón se enseñoreará de ti" (Gén. 3,16)- se han convertido en una suerte de designio fatal que ha acompañado a la mujer en las comunidades u organizaciones, tanto paganas como cristianas, en las cuales la mujer ha sido considerada un objeto sexual y de mercancía para el hombre, valorada por menos que esclavas y sirvientas, útil únicamente para dotar al hombre de prole y de alimento.

Era el varón mayor quien tomaba las decisiones. El modelo patriarcal (de raíces ancestrales) marcaba el tono en que se manejaban las relaciones. Aunque algunas mujeres eran educadas, lo eran solo para someterse dócilmente al varón, para casarse puras y castas y convertirse luego en abnegadas esposas que darían a su esposo muchos hijos y que se someterían a él totalmente "en amor". La situación de disparidad para la mujer se agravaba cuando se convertía en viuda o se separaba de su esposo por divorcio, pues debía volver a casa y someterse al varón como si fuera soltera. Los niños, dentro de un matrimonio, eran criados para obedecer órdenes del varón mayor, luego para gobernar, para hacer la guerra; y las niñas, por su parte, para someterse sumisamente a la voluntad del hombre.

En el Nuevo Testamento, se encuentran algunos textos que le confieren a la mujer un rol subordinado al hombre. Veamos en este sentido lo que escribe el apóstol San Pablo:

Vuestras mujeres callen en las congregaciones, porque no les es permitido hablar, sino que estén sujetas, como también la ley lo dice. Y si quieren aprender algo, pregunten en casa a sus maridos, porque es indecoroso que una mujer hable en la congregación (1 Cor. 14, 34-35).

Y si se quiere hablar de la relación de subordinación que debe mantenerse entre un hombre y una mujer, San Pablo también la expresa claramente en 1 Tim. 2, 11-15:

La mujer aprenda en silencio, con toda sujeción. Porque no permito a la mujer enseñar, ni ejercer dominio sobre el hombre, sino estar en silencio. Porque
Adán fue formado primero, después Eva; y Adán no fue engañado, sino que la mujer, siendo engañada, incurrió en trasgresión. Pero se salvará engendrando hijos, si permaneciere en fe, amor y santificación, con modestia.

En cuanto al tema religioso, se observa que la mujer tenía también un papel de sumisión a su esposo. El varón, por ejemplo, tenía obligaciones en el templo al cual, según la ley, debía asistir tres veces al año. La mujer era únicamente su acompañante y no tenía acceso a los lugares sagrados en el templo o en las sinagogas; el varón sí. La mujer contaba con un lugar reservado para ella (el atrio o patio exterior) desde donde solo podía escuchar las lecturas, pues no tenía derecho a realizar las lecturas, ni a hablar.

Aunque tales situaciones resulten indignantes para nosotras -y para nosotros-, no debe perderse de vista el contexto social, cultural, económico y religioso en que se dieron. Tampoco debe ignorarse que el Antiguo Testamento fue considerado el Libro de las Leyes y que, por su parte, el Nuevo Testamento fue el libro que contenía una serie de directrices para una comunidad de fe incipiente. Pero la fe necesita vivirse de manera diaria, y por ello actualiza permanentemente una tradición recibida; de otra forma caeríamos en una repetición mecánica, sin vivencia.

\section{Un vistazo al hoy desde la teología feminista}

En un contexto como el que acabamos de mencionar, es fácil ver reflejadas en el discurso bíblico situaciones de desigualdad para la mujer. $\mathrm{Y}$ ante ellas, las féminas hacen escuchar su voz, en un contexto sociocultural actual.

Irene Foulkes presenta lo que son las relaciones desde una perspectiva de género. Las define como el "conjunto de diferencias entre la conducta de varones y mujeres, determinado por nuestra cultura", que hacen que el hombre y la mujer "experimenten el mundo de manera diferente y desigual" (s.f.: p. 6). Al citar a Ferro, se refiere a las relaciones del sistema sexo/género de la siguiente forma: 
[... las mamás y los papás, así como la escuela, la iglesia y los medios de comunicación, se encargan de moldearnos para que nos comportemos de la manera que se considera apropiada para nuestro sexo. Esta conducta no la dicta el sexo biológico de la persona (...) La sociedad se encarga de reforzar este aprendizaje durante toda nuestra vida. (Foulkes, s.f.: p. 6).

En esta relación de varios elementos que confluyen en una sociedad androcéntrica, Foulkes también coincide en que el error histórico y universal de la teología patriarcal está en que la perspectiva masculina es elevada a imperativo categórico universal y natural en su apreciación del mundo y de lo sobrenatural.

Foulkes (s.f.: p. 7) sugiere que el tipo de tratamiento que se le debe dar al problema de interpretación del discurso bíblico, se resume en los siguientes pasos:

1. Descolonización de la mente, o lo que ella también llama "travestismo hermenéutico", mediante la deconstrucción y reconstrucción de nuestra propia identidad y la valoración de nuestro ser a partir de nuestra experiencia como mujeres, apartándonos de los valores androcéntricos.

2. Elaboración de las categorías con las que vamos a trabajar la relectura bíblica. Cita por ejemplo categorías de género, clase, raza/etnia, análisis de estructuras patriarcales y relaciones asimétricas.

3. Análisis de la exclusión de la mujer de los textos androcéntricos: a pesar de que con frecuencia se excluye a las mujeres en los discursos patriarcales de la Biblia, debemos preguntarnos -con base en nuestra propia experiencia- cuál sería nuestro rol, e intuir el de las mujeres en ese tiempo en la vida de la iglesia y su obra misionera.

4. Reconstrucción de la presencia femenina en los textos mediante la investigación del contexto socio-económico, político y religioso de la época en que se escribió el texto, para -a partir de ahí- reconstruir la labor de la mujer, que ha sido invisibilizada.
5. Contextualización del diálogo bíblico en nuestro contexto, para escuchar lo que el texto quiere decirnos hoy.

Históricamente, las mujeres también han sido relegadas de participar en la construcción de una cultura, y todavía más ferozmente de la vida oficial de la Iglesia como institución. Así las cosas, cuestiona Foulkes si "¿(...)la teología elaborada durante siglos solo por varones incorpora adecuadamente la perspectiva de las mujeres?" (s.f., p.7).

Letty M. Russell, por su parte, expone un abordaje más conciliador cuando señala que:

Ninguna de las definiciones de la Palabra de Dios es inconsistente con la tarea feminista de interpretación y cambio del lenguaje. El propósito de esa tarea es permitir que el mensaje bíblico sea escuchado como la Palabra de Dios, a pesar del contexto histórico patriarcal en el cual las historias de fe fueron formadas (Russell, 1997: p. 61).

Russell, más adelante, considera, al citar a McFague, que el "problema no es representar a Dios como Padre, sino haberlo convertido en la metáfora raíz para el cristianismo, reemplazando el mensaje del reino de Dios por un mensaje de patriarcalismo". (1997: p. 63).

Agrega la autora que el naciente paradigma feminista enfoca las relaciones de autoridad como la autoridad del compañerismo o de la comunidad, y añade otra serie de denominaciones como "compañerismo, amistad, comunidad, relación, mutualidad y matriarcado" (1997: p. 42). Cuando cita a Moltmann-Wendel, señala que la intención no es la inversión de un viejo paradigma de dominación, sino "buscar una forma alternativa de ordenar nuestra realidad y nuestro mundo para que sea menos dañina para los seres humanos, la naturaleza y toda la creación (...) alternativa más realista en un mundo que busca la autodestrucción con tal de que alguna nación o grupo pueda gritar "victoria"” (1997: p. 42).

Elisabeth Schüssler, desde una posición más radical y agitadora, hace una crítica muy fuerte a 
la teología patriarcal, al discurso bíblico en sí, y a la hermenéutica tradicionalmente kyriarcal.

¿Existen puntos medios en toda esta discusión? ¿Es posible lograr conciliaciones? Debo recordar aquí que el objetivo de este documento dista mucho de una posición feminista extrema y separatista. Sin obviar el fenómeno, planteo la interrogante sobre la posibilidad de dilucidar si los postulados de la perspectiva crítica de género permiten hallar evidencias que concilien posturas y que revaloren el papel de la mujer en el lenguaje bíblico. En este sentido, hago referencia a la postura de Irene Foulkes, pues llama a la reflexión y al análisis, cuando señala que "no significa lo mismo leer la Biblia hoy, en América Latina, y desde nuestra experiencia como mujeres, que leer la Biblia en otros tiempos y condiciones, y con otros ojos". (s.f.: p.3). Cada vez que se aborda la Biblia, desde una perspectiva nueva, tiene cosas nuevas que contar y nuevos aportes que hacer que vienen a corregir o a ampliar interpretaciones anteriores.

Antes de iniciar el análisis de algunos pasajes en el Nuevo Testamento, Rusell refresca la orientación de mi propuesta. Evidentemente, se debe partir de un análisis crítico, pero "sin derrumbar la tradición bíblica de la Iglesia como fuente de vida, sino mas bien construir una nueva casa (...) para redescubrir y reconstruir nuestra teología" (1997: p.76). Porque es "esta autoridad de la nueva creación de Dios la que posibilita la promesa de Gálatas 3:28 de que ya no hay judío, ni griego, ni esclavo, ni libre, hombre, ni mujer, porque todos son uno en Cristo Jesús" (1997: p.23).

\section{Jesús y su relación con las mujeres en los evangelios}

A lo largo de las narraciones en los cuatro evangelios, se encuentra un Jesús con una postura novedosa y, si se quiere, hasta radical, que escandaliza a los escribas, a los fariseos, a los publicanos e incluso a los mismos pecadores y pecadoras, quienes se acostumbraron a un estado de exclusión. Anota el Papa Juan Pablo II en su libro Carta a las Mujeres, que "Cristo fue ante sus contemporáneos el promotor de la verdadera dignidad de la mujer" (2004: p. 99). Dice por ejemplo Juan 4, 27 que "se sorprendían de que hablara con una mujer”. Y es que a Jesús le tenía sin cuidado la condición artificiosa con la cual la sociedad de aquellos tiempos se etiquetaba a sí misma: escribas, paganos, publicanos, recaudadores de impuestos, prostitutas, etc.; pues lo que a Él le importaba era la condición humana dentro del plan salvífico del Padre. Por eso decía que "los publicanos y las prostitutas os precederán en el reino de Dios” (Mt. 21, 31).

Jesús reconstruye la presencia femenina en los textos de la Biblia. Siendo aquí coherente con Foulkes y su propuesta de reconstrucción de la presencia femenina, es posible encontrar una nueva figura: la figura de una mujer de fe, ya no de pecado, ni de traición; la mujer se revalora $\mathrm{y}$, discursivamente, se presenta incluso como un modelo, un rol a seguir. Se hace natural pensar que entre los discípulos y seguidores de Jesús se encontraba una buena cantidad de mujeres, de diferente condición y edad.

En sus recorridos por las ciudades y aldeas, Jesús iba haciendo milagros y de esto eran testigos no solo los Doce, sino también las mujeres que lo acompañaban. Las mujeres se convierten en discípulas del mensaje mesiánico. Cuenta de ello da Lucas en su capítulo 8, versículos 2 y 3:

Lo acompañaban los Doce y también algunas mujeres que había sanado de espíritus malos o de enfermedades: María, por sobrenombre Magdalena, de la que habian salido siete demonios; Juana, mujer de Cuza, Administrador de Herodes; Susana y varias otras que lo atendian con sus propios recursos.

Las mujeres se transforman en discípulas de Jesús, y Jesús comparte con ellas sus enseñanzas; las mujeres también son parte importante en estas enseñanzas, y son a menudo utilizadas en la retórica del Maestro. En el caso de Lucas 21,1-4, Jesús ensalza a la viuda y la pone como modelo a seguir cuando señala que "esta pobre viuda depositó más que todos ellos. Porque todos dan a Dios de lo que les sobra. En cambio, la pobre dio lo que tenía para vivir". Si se ve más allá, tal actitud incluso pudo haber escandalizado a los ricos 
y fariseos que estaban en ese momento, pues la posición defensora que asumió Jesús ante la viuda contradecía el sistema jurídico y social, donde las viudas eran seres indefensos.

Jesús también resalta a las mujeres de fe $\mathrm{y}$, como ya había mencionado, las sitúa como ejemplos a seguir. En Marcos 5, 34, el evangelista relata la historia de una mujer que por largos años había sufrido de hemorragias y que sanó con solo tocar el manto de Jesús. En su interior, ella se dijo que si al menos lograba tocar su ropa, sanaría. Al darse cuenta, Jesús le dice: "Hija, tu fe te ha salvado, vete en paz..."

El Evangelista Mateo, en su capítulo 15, versículo 28 , también muestra un hecho de fe. Se trata de una mujer cananea que le pide socorro a Jesús para la curación de su hija. Este, ante el argumento de la mujer, le responde: "Mujer, grande es tu fe; que te suceda como deseas".

En los evangelios aparece también un Jesús solidario con las emociones humanas y que comparte los sufrimientos de la Humanidad. Jesús se conmueve ante el sufrimiento de las mujeres y practica milagros dirigidos a la mujer doliente, a la mujer pecadora, a la mujer enferma y que sufre; las libera a todas de su carga. En el Evangelio de Lucas, capítulo 13, versículo 11, se narra la curación de una mujer que estaba poseída y que "un espíritu la tenía enferma, estaba encorvada y no podía de modo alguno enderezarse". $\mathrm{Al}$ encontrarse con una viuda (Lucas 7,13), cuyo único hijo había muerto, Jesús se solidariza con el dolor de la mujer; y no solo la conforta, sino que devuelve al hijo a la vida.

El repertorio discursivo de Jesús en el Nuevo Testamento, así como su comportamiento, evidencia (siguiendo el esquema de Foulkes) una deconstrucción del entorno cultural de la época, y permite una nueva construcción sobre la base de otra categoría: género. Jesús, por tanto, no evidencia discriminación alguna hacia la mujer. Todo lo contrario, rinde respeto y honor a su dignidad, aún cuando sean "pecadoras" o "impuras" para los ojos de aquellas sociedades. Mediante el discurso de Jesús, la mujer es revalorada, sin importar la condición o posición que le otorgue la sociedad patriarcal en la cual se desenvuelve. Jesús, de antemano, ya sabe lo que hay en el corazón de cada uno; sabe lo que es justo ante los ojos de Dios.

Véase el caso que se presenta en Juan 4, 7-27, y que resumo de la siguiente manera: se trata de una mujer samaritana que lleva una vida licenciosa. Ha tenido ya cinco maridos, y su sexta pareja no es su marido. Jesús sabe todo esto. Sin embargo, la mujer se acerca al pozo donde está sentado Jesús para sacar agua. Él le pide agua y ella se escandaliza, pues a un judío no le es lícito dirigirse a un samaritano. A Jesús esto le tiene sin cuidado y entablan un diálogo sobre los dones que Él, como Hijo del Altísimo, tiene para la Humanidad (refiriéndose al Agua Viva). Al referirse al "marido" de la mujer, el asombro de ella no tiene límites, pues Jesús le hace ver que ya Él sabe su condición.

A Jesús poco le importa la opinión común y condenatoria de su época; acepta y perdona a aquellas a quienes la sociedad tacha de pecadoras. La mujer es invisibilizada a partir de su condición de pecado, concebido desde una plataforma patriarcal. Jesús, a través del perdón, las visibiliza, como diría Faulkes. La figura de la mujer entonces se reconstruye. Eso sí, Jesús establece una alianza; hay un contrato de por medio: "Vete y no peques más". Así se muestra por ejemplo en Juan 8, 3-11. En este pasaje, una mujer adúltera es llevada ante Jesús para que sea condenada según la Ley de Moisés. Jesús ignora a la multitud, la cual poco a poco se va retirando y deja a la mujer sola ante Él. El Maestro le dice: "Yo tampoco te condeno. Vete y no vuelvas a pecar en adelante". Lucas, en su capítulo 7, versículos del 37 al 47, presenta a un Jesús que está cenando en la casa de un fariseo cuando Magdalena entra y, llorando, le enjuaga los pies, se los perfuma y se los seca. El fariseo se escandaliza y piensa que si Jesús supiera quién es esa mujer, no le permitiría que se acercara. Sin embargo, Jesús lo deja atónito cuando se dirige a la pecadora: "Quedan perdonados tus muchos pecados, porque has mostrado mucho amor". 
La mujer tiene un papel trascendental en la Redención, no solo por el rol decisivo de María, la Madre de Jesús, sino porque Él decide presentarse a tres mujeres una vez resucitado, y no a sus discípulos. Es a ellas a quienes Jesús encomienda llevar la Buena Nueva, la de la Resurrección, y comunicársela a sus discípulos. Marcos, en su capítulo 16, versículos del 1 al 3, menciona quiénes eran esas mujeres: María Magdalena, María, madre de Santiago, y Salomé.

El Plan de Dios se lleva a cabo, según el Nuevo Testamento, mediante el nacimiento, la muerte y la resurrección de Jesucristo. No hubiera sido posible que este Plan se concretara sin la intervención de María. A pesar de que el discurso pareciera dar a entender que el pecado entró al mundo por una mujer, la salvación se hizo efectiva también por medio de una mujer.

Es por la trascendencia indiscutible que encierra el papel de María que parte de este análisis contempla la revaloración del papel de la mujer a partir de la imagen de María. Es a partir de la Anunciación cuando ya Dios se encarna; el "verbo se hace carne para habitar en nosotros", dice Juan 1,14. Ya no es con las palabras de Dios a través de los profetas, sino a través del "sí" de María, que se logra tal comunión con Dios y se alcanza el plan salvífico.

Al dar su "sí", María expresa una respuesta de fe, posible únicamente como un don del Espíritu Santo. Pero, asimismo, la mujer, en el símbolo de María, expresa también su libre voluntad, y al hacerlo, destaca además la participación plena del yo personal y femenino. En este sentido, cabría la pregunta: ¿cómo se manifiesta este "yo" personal y femenino en una sociedad contemporánea?

\section{Interrogantes finales}

Si se ha evidenciado en este breve análisis que el discurso que maneja Jesús en el Nuevo Testamento no es para nada patriarcal, entonces me cuestiono si los argumentos fanáticos sexistas y de género en torno a las interpretaciones del discurso bíblico son resultado de todo un proceso cultural, económico e ideológico, descontextualizado del mensaje divino. Pienso más bien que los discursos han sido acomodados convenientemente para cumplir con un proceso social que nos moldea y nos deforma. Tales procesos de subjetivación han sido realizados históricamente a través de las instituciones sociales más importantes: la escuela, la iglesia y la familia.

Cabría preguntarse: ¿cuán deforme está nuestra cultura y nuestra sociedad en manos del hombre y la mujer?

Creo que las palabras de Foulkes son muy acertadas para enfatizar la necesidad de una relectura de la Biblia. Afirma que "toda lectura de la Biblia es una relectura, es decir, un nuevo acercamiento a las Escrituras, con preguntas nuevas que surgen de las condiciones en el mundo y de la vida de las personas" (s.f.: p. 4). Vista así, la Biblia no fue escrita para darnos respuestas ante la vida, la muerte o la fe; por el contrario, plantea una serie de inquietudes que se resuelven a la luz de la fe y que son abordadas dentro de mi contexto, de mi cotidianidad. La riqueza de esta diversidad de relecturas (esos otros ojos que señala Foulkes) es lo que permite, a mi criterio, brindar a la lectura bíblica pertinencia y vigencia.

Es claro que el discurso bíblico maneja un patrón que tiende a ser patriarcal y se evidencia, sin rebuscar mucho, patrones y relaciones que, como señala Shüssler, reproducen la opresión del más débil. Sin duda alguna, este discurso ha acompañado a la humanidad en su devenir durante siglos; sin embargo, afirmar que la Biblia maneja un discurso sexista o patriarcal es reducir a la mínima expresión todo el plan de salvación de Dios y su mensaje. No creo, por tanto, que este sea el mejor momento de señalar culpables y rasgar vestiduras. Más bien, es el momento de abrir espacios de relación y de diálogo entre la fe, el conocimiento histórico y las diversas teologías, que fomenten un discurso teologal inclusivo: de la persona pobre, de la persona marginada, de la mujer, sobre la base de las experiencias contextuales que les hacen personas.

Aunque algunas feministas traten de rechazar el cristianismo al argumentar que es algo totalmente patriarcal, que la cristología engendra 
construcciones de identidad androcéntricas, y que profundiza la autoalienación patriarcal de las mujeres, considero que la imagen del Jesús histórico es conciliadora, pues predicó con sus actos el amor de Dios, llevó esperanza y solidaridad a los pobres y los despreciados, rompió con los patrones sociales de su época aceptando y perdonando a publicanos, prostitutas, cobradores de impuestos; llevó consuelo y la promesa del Reino de Dios a las viudas, los huérfanos y los desvalidos. Su muerte y resurrección trajo la salvación y nos hace compartir victoriosos las promesas de un estado de gracia permanente. En estos tiempos, es en sí su práctica liberadora como Jesús vivo, y no en su condición humana de varón, lo que cuenta al momento de hacer una relectura de los textos bíblicos. Tratar de revertir la condición biológica de Jesús, o pretender revertir la ontología de Dios, haciéndolo mujer, sería caer en el mismo error metodológico de los modelos patriarcales.

Cierro con las palabras de Schüssler cuando cita a Grant: "Lo que importa no es la masculinidad de Jesús, sino su opción por los pobres y su solidaridad con los marginalizados" (2000: p. 79).

\section{Bibliografía}

Casciano Ramírez, José María. (1983). Exegesis Bíblica, Hermenéutica y Teología. Ediciones Universidad de Navarra (EUNSA). Madrid, España.
Charpentier, Etienne. (2001). Para Leer el Antiguo Testamento. Editorial Verbo Divino. Navarra, España.

Chaves, Ronald. (2004). La restauración de la posición de la mujer en el reino de dios. Producciones Avance Misionero Mundial. San José, Costa Rica.

De Lima Silva, Silvia Regina. (2001). En territorio de fronte$r a$. Departamento Ecuménico de Investigaciones (DEI). San José, Costa Rica.

Foulkes, Irene. (s.f.). Primeros pasos en la relectura bíblica desde la perspectiva de género. CLAI, Secretaría de familia, mujeres y niños. .

Gareth, Jones, (2007). The Blackwell Companion to Modern Theology. Blackwell Publisching, MA.

Juan Pablo II, Papa. (2004). Carta a las mujeres. Ediciones Promesa. San José, Costa Rica.

La Nueva Biblia Latinoamericana. (s.f.). VII Edición. (s.l.) Ediciones Paulinas.

Richard, Pablo. (2002). Guía de estudio para el curso: Introducción a las Sagradas Escrituras. San José, Costa Rica.

Russell, Letty M. (1997). Bajo un techo de libertad: la autoridad en la teología feminista. Departamento Ecuménico de Investigaciones (DEI). San José, Costa Rica.

Schüssler Fiorenza, Elisabeth. (2000). Cristología Feminista Crítica. Jesús, hijo de Miriam, Profeta de la Sabiduría. Editorial Trotta. Madrid, España.

Sistema de Estudios de Posgrado UNED. (2007). Antología del curso Nuevo Testamento: contexto histórico-literario. San José, Costa Rica. 
- 